\title{
The Effect of Message Valence on e-WoM Spread: A Moderated Mediation Analysis
}

\section{Edin Guclu Sozer ${ }^{\mathrm{a}}$}

Abstract: This study aims to examine the effect of e-WoM message on the intention level of consumers to spread the word to other consumers in the presence of a moderated mediation interaction effect between risk perception and uncertainty

Keywords: e-WoM, Message Valence, Perceived Risk, Uncertainty Avoidance

JEL: M30, M31, M37

Received : 24 November 2018 Revised : 30 January 2019

Accepted : 06 February 2019

Type : Research

\section{Introduction}

The fast adoption of internet among consumers as a means of both communication and transaction, led to the development of platforms which are used for different purposes including socializing, information sharing as well as e-commerce. Social media, blogs and consumer forums are those powerful tools which consumers use to share their opinions as well as experiences with brands, products or services. This content, namely User Generated Content (UGC), when it includes any positive or negative statement about the brands, its products or services and shared with public, it is called as electronic word of mouth - e-WoM (Thurau \& Walsh, 2003). Active and extensive usage of these platforms led the e-WoM communication to be an important reference point for consumers, which is eventually turned into an important factor affecting the purchase decisions (Stauss, 1991). Consumer surveys also confirm that consumers use e-WoM content as a reference before making their purchases and their decision-making is influenced by the evaluations of other consumers (Cheung \& Thadani, 2012).

As a reaction to the changing dynamics of marketing ecosystem and consumer behavior, brands employed digital media as a part of their communication mix and started to allocate a considerable portion of their communication budget to digital advertisement. According to eMarketer (2017), the share of total 
global digital media communications investment is expected to reach at $50 \%$ of the global marketing communications investment, indicating a significant shift from its current level at 39\% as of 2017.

When we consider digital environment, we can list three types of media, namely, owned, paid and earned media, which can be regarded as the tools affecting the brand performance in cognitive, affective and conative levels of consumer behavior. Owned media is the content generated by the brand and disseminated through its own communication channels such website or social media page (Xie \& Lee, 2015). When the same content generated by the brand is placed into a third-party platform in exchange for a fee paid to platform owner, it is called paid media. Finally, earned media, is defined as a user generated content initiated in a third-party platform such as customer review sites, blogs, online forums involving the evaluation of the brand, its products or services (Stephen \& Galak, 2002).

Although all three types of media have considerable effect on the cognitive, affective and conative levels of consumer behavior, a special focus on earned media, e-WoM in particular, is needed due to its increasing effect on consumer purchase behavior (Rishika, Kumar, Janakiraman, \& Bezawada, 2013). Three factors need to be considered when we try to explain the increasing effectiveness of e-WoM on consumer behavior: Risk, Uncertainty avoidance and Spread. Consumers perceive a high risk when the consequences of their purchases are uncertain, and this situation leads to a possibility of physical or non-physical losses (Siegrist, Gutscher, \& Earle, 2005). As the Uncertainty Reduction Theory suggests, they search for ways to eliminate the uncertainty about the consequences of their purchases and ultimately reduce the risks associated with the purchase situation (Berger \& Calabrese, 1975). One-way consumers do this is to engage in e-WoM activities and get the required information to eliminate the uncertainties.

There are many studies in the literature dealing with the adoption of e-WoM (Goh, Heng, \& Lin, 2013; Yan et al., 2016) and its effects on various performance criteria such as introduction of new products (Arndt, 1967), attitude formation (Bone, 1995), purchasing decisions (Duan, Gu, \& Whinston, 2008), customer loyalty (Yoo, Sanders, \& Moon, 2013) and sales performance (Chevalier \& Mayzlin, 2005). However, careful investigation of the current literature shows that there is a lack of studies exploring the interdependent relationship between e-WoM message content, customer's risk perception level, uncertainty avoidance level and their intention to spread the word.

This study aims to examine the effect of two types of e-WoM message content, negative or positive, on the intention level of consumers to spread the word to other consumers in the presence of a moderated mediation interaction between risk perception and uncertainty avoidance levels of consumers. It is proposed that negative message contents will lead to higher levels of e-WoM spread intention which in turn is mediated by the perceived risk level of consumers. The study further proposes that uncertainty avoidance level of consumers will have a moderating effect on the relationship between e-WoM message and perceived risk. Thus, exploring this relationship will fill a gap and consequently contribute to the marketing literature.

\subsection{The Effects of e-WoM Message and Its Valence on Consumers' Intention to Spread the Word}

Consumer generated online content, whether it is a review or social media post, serves as a tool of decision making regarding the purchases of products or services. Consumers prefer to review the comments to learn about the features, quality and performances of products and services which help them to mitigate the risk associated with the purchase situation (Lee, Park, \& Han, 2008). In this respect, online information, that is e-WoM, affects consumer behavior and shapes their product preferences (Senecal \& Nantel, 2004). This effect is empirically validated by the numerous studies for different outcomes including sales (Chen, Wu, \& Yoon, 2004; Duan et al., 2008), purchase decisions or intentions (Park \& Kim, 2008; Park \& Lee, 2009) and attitude (Doh \& Hwang, 2009; Purnawirawan, Pelsmacker, \& Dens, 2012).

An important behavioral outcome of being exposed to e-WoM messages is to spread this information to other consumers in the community (Lee \& Youn, 2009; Sohn, 2009). This behavior is substantialized on the grounds of Social Exchange Theory which suggests that benefits and costs are the two outcomes of the interactions between the two parties in the market (Thibaut \& Kelley, 1959; Homans, 1958; Blau, 1964). Security, social approval and value are the three benefits which are expected to be received at the end of 
these interactions (Lambe, Wittmann, \& Spekman, 2008). The costs of receiving these benefits are efforts, time and money (Dwyer, Schurr, \& Oh, 1987). Consumers seek for exchanges that maximize the benefits and minimize the costs of these interactions to continue to their relationship (Blau, 1964).

Adapting the theory into the e-WoM communication dynamics, we can infer that in case consumers have a positive experience with the brand they become motivated to reward the brand as well as other consumers in the community by referring the brand via their messages (Yap, Soetarto, \& Sweeney, 2013). Similarly, when customers become dissatisfied, they prefer to share their negative opinions about the brand to incur costs to the brand and prevent other consumers from the same negative consequences (Ward \& Ostrom, 2006). In the light of the theoretical ground as well as the findings in the literature, we believe that exposure to e-WoM messages will motivate consumers to spread the word. This leads us to propose the following hypotheses:

$\mathrm{H}_{1}$ : Exposure to e-WoM messages will result in spreading the word to other consumers.

$\mathrm{H}_{2}$ : e-WoM message valence will have differing levels of influence on the intention to spread the word.

\subsection{The Effects of e-WoM Message and Its Valence on Consumers' Perceived Risk}

Perceived risk is defined as the nature and amount of risk perceived in a purchasing situation (Cox \& Rich, 1964). This construct is mainly composed of two parts, which are uncertainties about and severity of possible outcomes of an action (Aven \& Renn, 2009). The relationship between communication process and perceived risk can be explained on the grounds of uncertainty reduction theory (Berger \& Calabrese, 1975). Generally, parties involve into a communication process for reducing the uncertainty and understand the possible consequences of an action (Bettman, 1973). When there is a high level of uncertainty associated with unpredictable outcomes, perceived risk level increases. This leads to search for information for clarifying the consequences and consequently reducing the perceived risk level (Kellerman \& Reynolds, 1990). When we adapt this theory into the e-WoM communication process, we can conclude that consumers provide their feedback and share their opinions with other consumers to get required information and consequently reduce the uncertainties and perceived risk level associated with a purchase decision.

E-WoM messages, which transmit the feedback of other consumers in the community, provide the information needed by the consumers to complete their purchase decision (Guo, 2001). These messages have considerable impact on consumer behavior depending on their valence (Dorlin, 1985; Harrison-Walker, 2001). Thus, we believe that being exposed to e-WoM messages will have a significant effect on perceived risk level of consumers, which in turn is expected to alter their behavior. Previous studies also confirm this effect of e-WoM messages on perceived risk levels of consumers in offline context (Chen \& Dubinsky, 2003; Murray, 1991) and in online context (Lin et al., 2009; Sweeney, Soutar, \& Mazzarol, 2014; Parikh, Behnke, Vorvoreanu, Almanza, \& Nelson, 2014). This leads us to propose the following hypotheses:

$\mathrm{H}_{3}$ : Exposure to e-WoM message will have a significant impact on the perceived risk level of consumers.

$\mathrm{H}_{4}$ : e-WoM message valence will have differing levels of influence on the perceived risk level of consumers.

The effect of perceived risk on the intention to spread the word is another relationship which needs to be investigated. This relationship can be substantialized on the grounds of decision and regret theories. Decision theory suggests that people are sensitive about their self-image when they make decisions (Lin \& Fang, 2006). In this respect they hesitate to make decisions which may harm their self-image in the community. On the other hand, regret theory suggests that people not only try to estimate the outcome of their decisions but also, they compare the outcome with other alternative decisions would be made before the final decision (Bell 1982; Loomes \& Sugden, 1982; Josephs, Rose \& Tafarodi, 1992).

Combining two theories and applying it into the e-WoM's effect on the intention to spread the word, we believe that consumers, being motivated to protect their self-image and prevent regret, will hesitate to 
spread the word when they perceive high level of risk associated with the purchase decision. The findings of the current studies in the literature provide evidence on the inverse relationship between risk perception and intention to spread the word (Lampert \& Rosenberg, 1975; Stone, Yates, \& Caruthers, 2002; Beisswanger, Stone, Hupp, \& Allgaier, 2003). This leads us to propose the following hypotheses:

\section{$\mathrm{H}_{5}$ : Perceived risk will have a significant impact on the intention of consumers to spread the word. \\ $\mathrm{H}_{6}$ : Higher levels of perceived risk will lead to lower levels of intention to spread the word.}

\subsection{The Mediating Role of Perceived Risk}

The differential effect of the positive or negative e-WoM messages - the message valence on consumer behavior, received a considerable attention and many studies have been conducted on this subject (Lee \& Youn, 2009; East, Hammond, \& Lomax, 2008; Park \& Lee; 2009). The effect of message valence, whether it is positive or negative, can be substantialized on the grounds of Hull-Spence Theory (Hull, 1943, 1958; Hull et al., 1940; Spence 1956, 1960). The theory suggests that when an argument is strong which means, purely positive or negative, will have stronger effect on consumer behavior compared to messages with mixed composition. However, Hull-Spence theory does not underline the differential effect between pure positive or negative arguments. This effect can be grounded in Prospect Theory, which explains the psychological mechanism underlying the differential effect between positive and negative e-WoM messages. Prospect theory suggests that people become risk averse in cases where there is a possibility to gain something, and on contrary they become risk takers when there is a possibility of losing something (Kahneman \& Tversky, 1984). Thus, applying the theory into the purchase decision context, which is a kind of reward-seeking case, we believe that consumers become selectively more attentive to negative messages compared to positive ones since there is a risk involved in the situation (Floh, Koller, \& Zauner, 2013). Moreover, the role of diagnosticity also explains how consumers react differently to negative information on brands or products compared to positive ones (Skowronski \& Carlston 1989; Herr, Kardes, \& Kim, 1991). Based on this principle, negative information obtains higher weight than positive information in consumers' evaluations since negative one is regarded as being more diagnostic about a possible risk (Bone, 1995).

Many studies in the literature reported that negative message valence has higher impact than positive ones (Fiske 1980; Skowronski \& Carlston 1987; Chiou \& Cheng 2003). However, there are also conflicting results in the literature reporting non- significant or reverse direction effects (East et al., 2008; Park \& Lee, 2009; Floh et al., 2013). Thus, the findings are inconclusive and needs to be investigated further. In the light of the theoretical ground as well as the findings in the literature, we believe that the perceived risk will have a mediating effect on the relationship between e-WoM exposure and intention to spread the word by differentiating this effect in terms of e-WoM valence. This leads us to propose the following hypothesis:

$\mathrm{H}_{7}$ : The impact of e-WoM messages on intention to spread the word will be mediated by the perceived risk level of consumers.

\subsection{The Moderating Role of Uncertainty Avoidance}

A widely acknowledged definition of culture is provided by Hofstede (1980) as "the collective programming of the mind which distinguishes the members of one group or category of people from others" composed of shared norms, rules and values internalized by the members of the society (Singelis, Triandis, Bhawuk, \& Gelfand, 1995). Previous conceptualizations of culture resulted to the creation of six dimensions underlying the cultural orientation, namely individualism versus collectivism, masculinity versus femininity, power distance, uncertainty avoidance, long-term orientation and indulgence versus restraint (Hofstede, 1980; Hofstede \& Bond, 1988; Hofstede, Hofstede, \& Minkov, 2010).

Although culture is a construct which its effects are generally investigated on the group or national

level, considering that different individuals may have different backgrounds and consequently these different backgrounds may influence their cultural orientation, it can be also investigated at the individual level (Straub, Loch, Evaristo, Karahanna, \& Srite, 2002). Thus, we can state that cultural orientations shape how 
people communicate and behave and consequently affect their social interactions (Gudykanst et al., 1996). E-WoM communication, which is by nature a social engagement between two or more parties, is also subject to the influence of cultural orientations (Chu \& Choi, 2011). Even though there are numerous studies in the literature which measure the influence of culture on the social media context at the national level, number of studies which involve in measuring this influence at the individual level are scarce (Lee et al., 2018). This study focuses on the Uncertainty Reduction dimension of cultural orientation at the individual level and targets to explore its moderator role on the mediating effect of perceived risk.

As a cultural characteristic, uncertainty reduction is a psychological reaction of being less comfortable in cases of unstructured, novel, unknown, surprising or unusual situations (Hofstede, 1980). Thus, high uncertainty avoidance causes resistance towards changes such as adoption of new products since this decision bears some level of risk (Yeniyurt \& Townsend, 2003; Yaveroğlu \& Donthu, 2002). Consumers which value uncertainty reduction are risk sensitive and they are expected to take actions which may help them to mitigate the risks associated with a particular situation (Kale \& Barns, 1992). Their uncertainty reduction level influences how they perceive the risk that is higher levels of uncertainty reduction leads to higher levels of perceived risk (Chakrabarti \& Baisya, 2009). One way of reducing uncertainties and mitigating the risks is to receive support from others in the consumer community (Schumann et al., 2010). Thus, the level of uncertainty reduction, whether is high or low, will lead to different levels of motivation for both seeking and providing opinions (Dawar, Parker, \& Price, 1996; Money, Gilly, \& Graham, 1998; Lam, Lee, \& Mizerski, 2009).

In the light of the theoretical ground as well as the findings in the literature, we believe that the mediation effect of perceived risk on the relationship between e-WoM message valence and intention to spread the word will be moderated by the uncertainty avoidance level of consumers. This leads us to propose the following hypothesis:

$\mathrm{H}_{8}$ : Uncertainty avoidance moderates the perceived risk mediated impact of e-WoM message valence on intention to spread the word.

\section{Aim and Research Methodology}

\subsection{Research Design}

In this study, an experimental design is implemented to explore the effects of e-WoM message valence on the intention to E-WoM spread, the mediating effect of perceived risk on this relationship and the moderator effect of uncertainty avoidance on the perceived risk mediated relationship between e-WoM message valence and the intention to E-WoM spread. Sports shoes was the product category employed in the experimental study. This brand was a hypothetical one, which consumer does not know for sure, to eliminate any biases, whether positive or negative, generated by the previous brand experience of consumers.

The manipulated factor in the experimental design was e-WoM message content, which is valence, composed of negative or positive opinions of consumers. Subjects were divided into two groups and each group exposed to different types of e-WoM message, positive and negative. Groups were exposed to e-WoM messages via an online consumer review web site which was generated for this study. Under each group there were twenty-five consumer feedbacks about the sports shoes brand and depending on the group type, messages were manipulated to be composed of overwhelmingly positive or negative messages but not totally in one direction.

\subsection{Sampling and Procedure}

The subjects of this study were identified as the university students in Istanbul, Turkey. Total number of questionnaires distributed were one hundred forty, and twenty of these with missing data were eliminated, resulting one hundred twenty complete questionnaires. In the first part of the questionnaire, subjects were provided a scenario describing that they were making a research in the internet about a sports shoe brand for a possible future research. Then each group was exposed to the manipulated factor which 
includes negative or positive e-WoM messages. In the next section, subjects were asked to provide their answers regarding the items measuring perceived risk level for this purchase decision, their uncertainty avoidance level and finally, their intention to E-WoM spread.

\subsection{Operationalization of Variables}

Each scale employed in this study was validated by the respective authors. The instrument was composed of both Likert Type as well as semantics scales depending on the measurement variable. Six items seven-point Likert Type Intention to spread scale was adopted from the work of Sun, Youn, Wu, \& Kuntaraporn (2006). Perceived Risk was measured by adopting the scale developed and validated by Bearden \& Shrimp (1982). Nine points semantic scale was composed of three items. Finally, uncertainty avoidance has been adopted from the works of Jung \& Kellaris (2004), a modified version of the scale validated by Jung (2002).

The validity and reliability of the operationalized scales were provided with the respective confirmatory factor analysis (CFA) and reliability analysis. The results of the CFA including 13 variable items confirmed the construct validity of the scales. Fit indices $(X 2 / D F=1.479, C F I=0.974, I F I=0.974, R M S E A=0.056$ ) including CMIN/DF value and others were within the acceptable range reported in the respective literature (Bagozzi \& Yi, 1990).

Table 1. Confirmatory Factor Analysis Results

\begin{tabular}{|l|c|c|c|}
\hline Variables & Items & $\begin{array}{c}\text { Standardized } \\
\text { Factor Loads }\end{array}$ & $\begin{array}{c}\text { Unstandardized } \\
\text { Factor Loads }\end{array}$ \\
\hline E-WoM Spread & WoM1 & 0.704 & 0.989 \\
\hline & WoM2 & 0.772 & 1.197 \\
\hline & WoM3 & 0.704 & 1.070 \\
\hline & WoM4 & 0.627 & 0.937 \\
\hline & WoM5 & 0.735 & 1.032 \\
\hline & WoM6 & 0.772 & 0.977 \\
\hline & WoM7 & 0.795 & 1.000 \\
\hline Perceived Risk & RI1 & 0.756 & 0.956 \\
\hline & RI2 & 0.830 & 1.119 \\
\hline $\begin{array}{l}\text { Uncertainty } \\
\text { Avoidance }\end{array}$ & RI3 & 0.629 & 1.000 \\
\hline \multicolumn{2}{|l}{ UNA1 } & 0.857 & 0.854 \\
\hline & UNA2 & 0.743 & 0.803 \\
\hline p<0.01 for all items & UNA3 & 0.968 & 1.000 \\
\hline
\end{tabular}

Convergent validity of the scales used in the study was confirmed by calculating Average Variance Extracted (AVE) values. Byrne (2010) reports values above 0.5 as a satisfactory level of convergent validity. The results of the calculation produced all values above this minimum threshold and confirmed the convergent validity of the scales. The comparison between the correlated components and the square roots of AVE scores, confirmed the discriminant validity of scales. Finally, both Cronbach $\alpha$ and composite reliability scores were at the acceptable levels confirming the scale reliabilities (Fornell \& Larcker, 1981). 
Table 2. Validity and Reliability Checks

\begin{tabular}{|l|c|c|c|}
\hline Variables & $\mathbf{1}$ & $\mathbf{2}$ & $\mathbf{3}$ \\
\hline E-WoM Spread & $(0.732)$ & & \\
\hline Perceived Risk & $0.522^{* *}$ & $(0.743)$ & $(0.861)$ \\
\hline Uncertainty Avoidance & $0.368^{* *}$ & $0.592^{* *}$ & 0.895 \\
\hline \multicolumn{4}{|l|}{0.741} \\
\hline Composite Reliability & 0.889 & 0.785 & 0.892 \\
\hline $\begin{array}{l}\text { Average Variance } \\
\text { Extracted }\end{array}$ & 0.536 & 0.552 & 0.768 \\
\hline Cronbach $\alpha$ & 0.890 & & \\
\hline \multicolumn{4}{|l|}{$* *$ Correlation is significant at the 0.01 level (2-tailed) } \\
\hline Diagonals show the square root of AVEs \\
\hline
\end{tabular}

\subsection{Analysis}

Testing of the hypothesis in this experimental design was done by employing PROCESS SPSS macro which provides the asymmetric bootstrap confidence interval $(\mathrm{Cl})$ estimates for the measurement of relative indirect relationships, the mediation effect (Hayes \& Preacher, 2013). The macro is preferred based on the suitability reference in the literature due to two reasons: First, it is tested and approved in many studies in the literature (Biesanz, Falk, \& Savalei, 2010) and secondly, does not make a normality assumption regarding the sample distribution of relative indirect effect (Hayes \& Scharkow, 2013). Relative total and direct effects were also measured using the same macro which generates the required regression equations.

\section{Findings}

3.1. Indirect effect of Message Valence on Intention to e-WoM Spread: Mediation effect of Perceived Risk

The analysis to test the mediation effect of perceived risk on the relationship between message valence and intention to E-WoM spread produced three estimation models which helps to test the hypothesis and explain the mediation effect. The details of the results of the mediation analysis are presented in Table 3.

Table 3. Mediation Model Outputs

\begin{tabular}{|c|c|c|c|c|c|c|c|c|c|}
\hline & \multicolumn{3}{|c|}{ Model 1} & \multicolumn{3}{|c|}{ Model 2} & \multicolumn{3}{|c|}{ Model 3} \\
\hline & \multicolumn{3}{|c|}{ E-WoM Spread (Y) } & \multicolumn{3}{|c|}{ Perceived Risk (M) } & \multicolumn{3}{|c|}{ E-WoM Spread (Y) } \\
\hline Antecedents & Coefficient & SE & $p$ & Coefficient & SE & $p$ & Coefficient & SE & $p$ \\
\hline $\begin{array}{l}\text { Message } \\
\text { Valence }\end{array}$ & $c_{1} \quad 0.905$ & 0.11 & $<0.001$ & $a_{1}-1.121$ & 0.10 & $<0.001$ & $c^{1}{ }_{1} \quad 1.177$ & 0.13 & $<0.001$ \\
\hline $\begin{array}{l}\text { Perceived } \\
\text { Risk }\end{array}$ & - & - & - & - & - & - & $b \quad 0.243$ & 0.07 & $<0.001$ \\
\hline \multirow[t]{3}{*}{ Constant } & $I_{y} \quad 3.407$ & 0.08 & $<0.001$ & $I_{m} 4.203$ & 1.00 & $<0.001$ & $I_{y} \quad 2.387$ & 0.32 & $<0.001$ \\
\hline & \multicolumn{3}{|c|}{$R^{2}=0.3513$} & \multicolumn{3}{|c|}{$R^{2}=0.3703$} & \multicolumn{3}{|c|}{$R^{2}=0.4054$} \\
\hline & \multicolumn{3}{|c|}{$F(1,118)=64, p<0.001$} & \multicolumn{3}{|c|}{$F(1,118)=69, p<0.001$} & \multicolumn{3}{|c|}{$F(1,118)=40, p<0.001$} \\
\hline
\end{tabular}


Model 1 estimates the total effect of message valence on the intention to spread the e-WoM message. The results indicate that message valence influences the intention to spread the e-WoM message of consumers $(R 2=0.3513, F(1,118)=64, p<0.001)$ which results in support of $H_{1}$. Another important indication of the model is that those consumers who will be exposed to positive e-WoM messages will have higher level of intention to spread the e-WoM message compared to negative messages $(B=0.905, p<0.001)$. This result leads us to support $\mathrm{H}_{2}$.

Model 2 includes the estimates of the effect of message valence on the perceived risk level of consumers. The results confirm that message valence influence the perceived risk level of consumers $\left(R^{2}=\right.$ $0.370, F(1,118)=69, p<0.001)$. Further analysis of the model shows that those who will be exposed to positive e-WoM messages will have lower level of risk compared to those who will be exposed to negative e-WoM messages $(B=-1.121, p<0.001)$. Thus, message valence has differing levels of influence on the intention to spread the e-WoM message. These two results lead us to support both $\mathrm{H}_{3}$ and $\mathrm{H}_{4}$.

The estimates of direct effects of message valence and perceived risk are provided in Model 3. The results confirm that perceived risk influences the intention to spread the e-word of consumers $\left(R^{2}=0.405\right.$, $F(2,117)=40, p<0.001)$. Thus, we support $H_{5}$. Moreover, those who are exposed to the same type of message, let's say positive, but they have higher level of perceived risk, are estimated to have higher their intention to spread the e-WoM message $(B=0.243, p<0.001)$. This finding is not consistent with $\mathrm{H}_{6}$ and consequently the hypotheses is not supported.

Measuring the indirect effect of message valence on intention to spread the word through perceived risk provides its mediator effect. This effect is the product of regression coefficients in Model 2 and Model 3. Since the regression coefficients have non-normal sampling distribution, as suggested by Hayes \& Preacher (2013), we applied a bootstrap confidence interval with 5,000 bootstrap samples. Indirect effect of message valence was calculated based on the following equation:

Indirect Effect Message Valence $=a b=-1.121(0.243)=-0.272$

The results show that the indirect effect confidence intervals for message valence are $95 \% \mathrm{Cl}=$ 0.4723 to -0.0929 . Confidence interval values are both below zero and this leads us to the conclusion that the indirect effect is negative. Additionally, confidence intervals do not include any zero value which confirms the mediated effect of message valence on e-WoM spread by the perceived risk level of consumers (Hayes \& Preacher, 2013). We report a partial mediation since total and direct effects are different from zero and statistically significant. This result leads us to support $\mathrm{H}_{7}$. The details of the results of this analysis are presented in Table 4.

Table 4. Indirect Effect of Message Valence on E-WoM Spread

\begin{tabular}{|l|c|c|c|c|}
\hline \multicolumn{3}{|c|}{ Message Valence $\longrightarrow$ Perceived Risk } & \multicolumn{2}{c|}{ E-WoM Spread } \\
\hline & Effect & Boot SE & Boot LLCl & Boot ULCl \\
\hline Perceived Risk (M) & -0.2720 & 0.0964 & -0.4723 & -0.0929 \\
\hline
\end{tabular}

\subsection{Moderation effect of Uncertainty Avoidance on Message Valence-Perceived Risk Relationship}

The results of the analysis to test the moderation analysis of uncertainty reduction on perceived risk level of consumers indicate that the product of message valence and uncertainty avoidance level was positively related to perceived risk level of consumers and this relationship is statistically significant $(y=0.5183, p<0.001)$. Calculation of the interaction effect is made by computing the slopes one standard deviation above and below of the uncertainty avoidance (Aiken \& West, 1991) and the results indicate that the relationship between message valence and perceived risk are stronger when uncertainty avoidance level is higher. Positive messages generate more positive and stronger effect on the increase of perceived risk level compared to negative messages when uncertainty avoidance level increases. This effect confirms the 
moderating effect of uncertainty avoidance level on the effect of message valence on the perceived risk level of consumers. The details of the results of the moderation analysis are presented in Graphical representation of the interaction effect is presented in Table 5 and graphical representation of the interaction effect is presented in Figure 1.

Table 5. Moderation Effect of Uncertainty Avoidance on Message Valence and Perceived Risk Relationship

\begin{tabular}{|l|c|c|c|c|c|c|}
\hline \multirow{2}{*}{ Predictor } & \multicolumn{5}{|c|}{ Mediator Variable Model: DV=Perceived Risk (M) } \\
\cline { 2 - 7 } & Coefficient & SE & $\mathrm{t}$ & $\mathrm{p}$ & $95 \% \mathrm{Cl}$ LL & $95 \% \mathrm{Cl}$ UL \\
\hline Message Valence (X) & -0.6733 & 0.1320 & -5.0713 & $<0.001$ & -0.9362 & -0.4103 \\
\hline Uncertainty Avoidance (W) & 0.4666 & 0.0730 & 6.3955 & $<0.001$ & 0.3221 & 0.6111 \\
\hline X*W & 0.5183 & 0.1460 & 3.5497 & $<0.001$ & 0.2291 & 0.8074 \\
\hline
\end{tabular}

Figure 1. Interaction Effect of Moderation

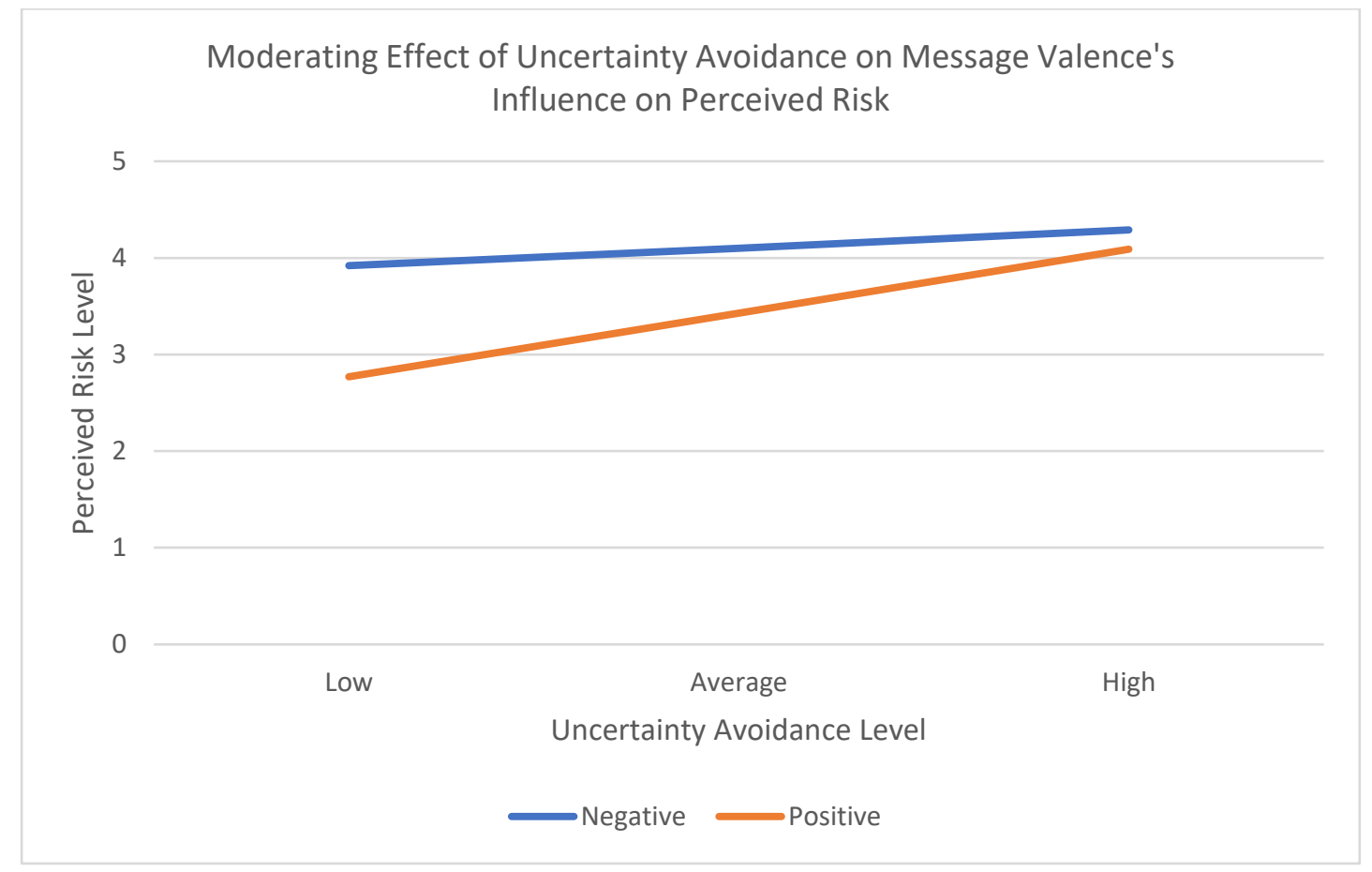

3.3. Conditional Indirect effect of Message Valence on Intention to e-WoM Spread: Moderated Mediation Effect

We proposed with Hypothesis 8 that uncertainty avoidance will moderate the indirect negative effect of message valence on e-WoM spread through perceived risk level of consumers. Testing of this effect is done by measuring the indirect effects of message valence on three different levels of uncertainty avoidance, namely low (-1 SD), average (mean) and high (+1 SD) levels. 
The Effect of Message Valence on e-WoM Spread: A Moderated Mediation Analysis

Table 6. Results of the Moderated Mediation Analysis

\begin{tabular}{|l|c|c|c|c|}
\hline \multirow{2}{*}{$\begin{array}{l}\text { Uncertainty } \\
\text { Avoidance }\end{array}$} & \multicolumn{4}{|c|}{$\begin{array}{c}\text { Conditional Indirect Effect of Message Valence on } \\
\text { Intention to Spread the Word }\end{array}$} \\
\cline { 2 - 5 } & Coefficient & SE & $95 \%$ Cl LL & $95 \%$ Cl UL \\
\hline Low (-1 SD) & -0.2782 & 0.1055 & -0.5246 & -0.0992 \\
\hline Average (M) & -0.1633 & 0.0637 & -0.3241 & -0.0633 \\
\hline High (+1 SD) & -0.0485 & 0.0492 & -0.1685 & 0.0313 \\
\hline
\end{tabular}

The results confirm that indirect negative effect of message valence on intention to spread the eWoM message is weaker when uncertainty avoidance level is average $(-0.16,95 \% \mathrm{Cl}=-0.3241$ to -0.0633$)$ compared to lower levels of uncertainty avoidance $(-0.27,95 \% \mathrm{Cl}=-0.5246$ to -0.0929$)$. On the other hand, confidence intervals for high level of uncertainty avoidance include zero value which indicates that this effect is not different from zero. As suggested by Hayes (2015), we calculated the index of moderated mediation which is proposed as a good indicator of moderated mediation effect. The calculation yields significant result $(0.12,95 \% \mathrm{Cl}=0.0381$ to 0.2687$)$ and this leads us to conclude that the indirect negative effect of message valence on intention to spread the e-WoM message through perceived risk is moderated by the uncertainty avoidance level of consumer. Thus, we found empirical evidence on the moderated mediation effect and support $\mathrm{H}_{8}$

\section{Discussion and Conclusion}

This study measured the effect of different e-WoM message contents, whether positive or negative, on the intention of consumers to spread the e-WoM message. Based on the proposed model, message valence goes through different levels of perceived risk and uncertainty avoidance and influences the intention to spread the e-WoM message. In this respect, there are several important findings of this study.

First, in line with the expectations, message valence has a positive direct influence on intention to spread the word (Ward \& Ostrom, 2006; Yap et al., 2013). Consistent with the existing literature, message valence is also found to have a positive significant effect on perceived risk (Sweeney et al., 2014; Parikh et al., 2014). Perceived risk, in turn, has a positive direct effect on the intention to spread the e-WoM message which is not consistent with the related hypotheses proposed by adapting decision and regret theories into the e-WoM context. This study contributes to the existing literature where the findings which explore this relationship are inconclusive since there are studies both reporting the inverse effect as well as positive influence of perceived risk on the intention to spread the word (Lampert \& Rosenberg,1975; Stone et al., 2002; Beisswanger et al., 2003; Lin \& Fang, 2006).

Another important finding of this study is related with the mediation role of perceived risk on the relationship between the message valence and intention to spread the E-WoM message. Relative to those exposed to negative messages, those consumers who read positive messages, show lower intention to spread the word because of the negative effect of these messages on the perceived risk level, which in turn leads to diminishing positive influence of perceived risk on intention to spread the word. Thus, the positive direct effect of positive messages turns into a negative indirect effect when perceived risk mediates this relationship. This result provides an important contribution to the literature.

Finally, uncertainty avoidance level is found to be effective on the perceived risk of consumers and it moderates the relationship between message valence and perceived risk. Thus, the negative effect of positive messages on perceived risk are transformed into positive when the uncertainty avoidance level is added as a moderator variable. Overall, we can conclude that when uncertainty avoidance level increases, the indirect negative effect of positive messages on intention to spread the word starts to diminish. In other words, the negative indirect effect of perceived risk mediated influence of positive messages, stabilizes with the 
uncertainty avoidance moderated effect. This finding is also an important contribution to the existing literature.

\section{Practical Implications}

One of the findings of this study suggests that when consumers are exposed to positive e-WoM messages, they are more likely to share this type of messages with other consumers in the community compared to when they receive negative messages. In this respect, marketers need to encourage their satisfied customers to share their positive opinions with other consumers in the market as much as possible, which in turn will motivate receiver customers to share these messages with other consumers. This will create an accelerated effect of positive e-WoM communication about the brand and its products which in turn is expected to positively influence the bottom line results.

Another finding of this study indicates that when consumers are exposed to positive e-WoM messages, these messages negatively influence their perceived risk level which in turn diminishes their intention to share these messages with other consumers. Thus, to create and sustain an accelerated stream of positive e-WoM communication, marketers need to manipulate the risk perception level of e-WoM receivers upwards, so they will be motivated to spread the word further. One way of succeeding this is recommended as to apply negative framing in marketing communications targeted to the e-WoM receiver consumer group to increase their perceived risk level regarding the purchase decision towards the selected products or services. Application of negative framing in the marketing communications, which focuses on the negative consequences of making a wrong decision, is expected to increase the perceived risk level and consequently balance the negative effect of positive messages on perceived risk level. Based on the findings of this study, this creative strategy becomes more crucial in case marketers target consumer groups with low uncertainty avoidance level which is expected to influence their perceived risk level negatively and consequently decrease their intention to share the e-WoM messages.

As a result, marketers who target to maximize the benefits of customer satisfaction, need to implement a two levels e-WoM communication strategy. In the first level, they need to construct a strong pool of positive e-WoM communication generated by their satisfied customers. To do this, they need to encourage their customers as much as possible with some incentives to share their positive opinions with other consumers in the community. Following the successful creation of large and positive e-WoM pool by existing customers, the second level of e-WoM communication strategy consists of expanding the message pool by motivating prospects to share these messages. This can be succeeded by manipulating their risk perception levels about the possible consequences of the wrong decisions using negative framing in the marketing communication messages, which in turn is expected to increase their intention to share these first level e-WoM messages.

\section{Limitations and Suggestions for Future Research}

One limitation of this study is related with the generalizability of the results since only one type and one category of products, namely sports shoe and shopping goods, was included in the experimental design. As other product categories such as specialty goods or different contexts such as services are more risk intensive, to increase the generalizability, testing of the same effects for different product categories as well as contexts would be appropriate.

In the future studies, measurement of the same effects in a cross country and generational contexts would also help to expand the scope of the current study and consequently contribute to the literature. 


\section{References}

Aiken, L. S., \& West, S. G. (1991). Multiple regression: Testing and interpreting interactions. Newbury Park, CA: Sage Arndt, J. A. (1967). Word of mouth advertising. New York: Advertising Research Foundation.

Aven, T., \& Renn, O. (2009). On risk defined as an event where the outcome is uncertain. Journal of Risk Research, 12, 1-11.

Bagozzi, R. P. (1975). Marketing as exchange. Journal of Marketing, 39, 32.

Bell, E. D. (1982). Regret in Decision Making Under Uncertainty. Operations Research, (30), 961-981.

Bearden, W. O., \& Shrimp, T. S. (1982). The use of extrinsic cues to facilitate product adoption. Journal of Marketing Research, 19, 229-239.

Beisswanger, A. H., Stone, E. R., Hupp, J. M., \& Allgaier, L. (2003). Risk taking in relationships: Differences in deciding for oneself versus for a friend. Basic \& Applied Social Psychology, 25(2), 121-135.

Berger, C. R., \& Calabrese, R. J. (1975). Some explorations in initial interaction and beyond: Toward a developmental theory of interpersonal communication. Human Communication Research, 1(2), 99-112.

Biesanz, J. C., Falk, C. F., \& Savalei, V. (2010). Assessing mediational models: Testing and interval estimation for indirect effects. Multivariate Behavioral Research, 45(4), 661-701.

Biswas, D., \& Biswas, A. (2004). The diagnostic role of signals in the context of perceived risks in online shopping: Do signals matter more on the web? Journal of Interactive Marketing, 18(3), 30-45.

Blau, P. M. 1964. Exchange and Power in Social Life. New York: John Wiley \& Sons, Inc.

Byrne, B. M. (2010). Structural equation modeling with AMOS. New York: Routledge Taylor \& Francis Group.

Chakrabarti, S., \& Baisya, R. K. (2009). Purchase of organic food: role of consumer innovativeness and personal influence related constructs. IIMB Management Review, 21(1), 18-29.

Chen, P. Y., Wu, S. Y., \& Yoon, J. S. (2004). The impact of online recommendations and consumer feedback on sales. Proceedings of the International Conference on Information Systems (pp. 711-724). Seattle, WA: Association for Information Systems.

Chen, Z., \& Dubinsky, A. J. (2003). A conceptual model of perceived customer value in e-commerce: A preliminary investigation. Psychology and Marketing, 20(4), 323-347.

Cheung, C. M. K, \& Thadani, D. R. (2012). The impact of electronic word of-mouth communication: A literature analysis and integrative model. Decision Support Systems, 54(1), 461-470.

Chevalier, J. A., \& Mayzlin, D. (2006). The effect of word of mouth on sales: online book reviews. Journal of Marketing Research, 43(3), 345-354.

Chiou, J. S, \& Cheng, C. (2003). Should a company have message boards on its web sites? Journal of Interactive Marketing, 17(3), 50-62.

Chu, S. C., \& Choi, S. M. (2011) Electronic word-of-mouth in social networking sites: A cross-cultural study of the United States and China, Journal of Global Marketing, 24(3), 263-281.

Chul, W. Y., Sanders, L. G, \& Junghoon, M. (2013). Exploring the effect of e-wom participation on e-loyalty in ecommerce. Decision Support Systems, 55, 669-678.

Cox, D. F., \& Rich, S. U. (1964). Perceived risk and consumer decision-making: the case of telephone shopping. Journal of Marketing Research, 1(4), 32-49.

Dawar, N., Parker, P. M., \& Price, L.J. (1996). A cross-cultural study of interpersonal information exchange. Journal of International Business Studies, 27, 497-516.

Doh, S. J, \& Hwang, J. S. (2009). How consumers evaluate e-wom (electronic word-of-mouth) messages. Cyberpsychology \& Behavior, 12(2), 193-197.

Dorlin, D. (1985). Although U.S. cars are improved, imports still win quality survey. The Wall Street Journal, December 16, 27.

Duan, W. J., Gu, B., \& Whinston, A. B. (2008). The dynamics of online word-of-mouth and product sales: An empirical investigation of the movie industry. Journal of Retailing, 84(2), 233-242.

Duan, W., Gu, B., \& Whinston, A.B. (2008). Do online reviews matter? An empirical investigation of panel data. Decision Support Systems, 45(4), 1007-1016.

Dwyer, F. R., Schurr, P. H., \& Oh, S. (1987). Developing buyer-seller relationships. Journal of Marketing, 51, 11-27. 
East, R., Hammond, K., \& Lomax, W. (2008). Measuring the impact of positive and negative word of mouth on brand purchase probability. International Journal of Research in Marketing, 25(3), 215-224.

eMarketer. 2018. Global ad spending report. https://www.emarketer.com. Accessed: June 2018.

Fiske, S. T. (1980). Attention and weight in person perception: The impact of negative and extreme information. Journal of Personality and Social Psychology, 38, 889-906.

Floh, A., Koller, M., \& Zauner, A. (2013). Taking a deeper look at online reviews: The asymmetric effect of valence intensity on shopping behaviour. Journal of Marketing Management, 29(5-6), 646-670.

Fornell, C., \& Larcker, D. (1981). Evaluating structural equation models with unobservable variables and measurement error. Journal of Marketing Research, 18(1), 39-50.

Goh, K. Y., Heng, C. S., \& Lin, Z. (2013). Social media brand community and consumer behavior. Information Systems Research, 24(1), 88-107.

Guo, C. (2001). A review on consumer external search: Amount and determinants. Journal of Business and Psychology, 15(3), 505-519.

Gudykunst, W. B., Matsumoto, Y., Ting-Toomey, S., Nishida, T., Kim, K. S., \& Heyman, S. (1996). The influence of cultural individualism-collectivism, self construals, and individual values on communication styles across cultures. Human Communication Research, 22, 510-43.

Harrison-Walker, L. J. (2001). The measurement of word-of-mouth communication and an investigation of service quality and customer commitment as potential antecedents. Journal of Service Research, 4, 60-75.

Hayes, F. A., \& Preacher, K. J. (2013). Statistical mediation analysis with a multicategorical independent variable. The British Journal of Mathematical and Statistical Psychology, 67.

Hayes, A. F., \& Scharkow, M. (2013). The relative trustworthiness of tests of indirect effects in statistical mediation analysis. Does method really matter? Psychological Science, 24, 1918-1927.

Hayes, A. F. (2015). An index and test of linear moderated mediation. Multivariate Behavioral Research, $50,1-22$.

Hennig-Thurau, T., \& Walsh, G. (2003). Electronic word-of-mouth: motives for and consequences of reading customer articulations on the Internet. International Journal of Electronic Commerce, 8, 51-74.

Herr, P. M., Kardes, F. R., \& Kim, J. (1991). Effects of word-of-mouth and product attribute on persuasion. Journal of Consumer Research, 17, 454-62.

Hofstede, G. (1980). Culture's consequences. Beverly Hills, CA: Sage.

Hofstede, G., \& Bond, M. H. (1984). Hofstede's cultural dimensions: an independent validation using Rokeach's values survey. Journal of Cross-Cultural Psychology, 15, 417-433.

Hofstede, G., Hofstede, G. J., \& Minkov, M. (2010). Cultures and organizations: software of the mind, revised and expanded (3rd ed.). New York, NY: McGraw-Hill.

Homans, G. C. (1958). Social behavior as exchange. American Journal of Sociology, 63, 597-606.

Hull, C. L. (1958). A behavior system: an introduction to behavior theory concerning the individual organism. New Haven, CT: Yale University Press.

Hull, C. L. (1943). Principles of behavior: an introduction to behavior theory. New York, NY: Appleton-Century-Crofts.

Hull, C. L., Hovland, C. I., Ross, R. T., Hall, M., Perkins, D. T., \& Fitch, F. G. (1940). Mathematico-deductive theory of rote learning. New Haven, CT: Yale University Press.

Josephs, R., Rose M., H., \& Tafarodi, W. R. (1992). Gender and self-esteem. Journal of Personality and Social Psychology, 63, 391-402.

Jung, J. M. \& James, K. (2004). Cross-national differences in proneness to scarcity effects: The moderating roles of familiarity, uncertainty avoidance, and need for cognitive closure. Psychology and Marketing, 21, 739-753.

Kahneman, D. \& Tversky, A. (1984). Choices, values, and frames, American Psychologist, 39(4), 341-350.

Kale, S. H., \& Barns, J. B. (1992). Understanding the domain of cross-cultural buyer-seller interactions. Journal of International Business Studies, 23, 101-132.

Kellerman, K., \& Reynolds, R. (1990). When ignorance is bliss the role of motivation to reduce uncertainty in uncertainty reduction theory. Human Communication Research, 17(1), 5-75.

Lam, D., Lee, A., \& Mizerski, R. (2009). The effects of cultural values in word-of-mouth communication. Journal of International Marketing, 17(3), 55-70. 
Lambe, C. J., Wittmann, C. M., \& Spekman, R. E. (2001). Social exchange theory and research on business-to-business relational exchange. Journal of Business-to-Business Marketing, 8(3), 1-36.

Lampert, S. I., \& Rosenberg, L. J. (1975). Word of mouth activity as information search: A reappraisal. Journal of the Academy of Marketing Science, 3(4), 337-354.

Larrick, R. P. (1993). Motivational factors in decision theories: The role of self-protection. Psychological Bulletin, 113(3), 440-450.

Lee, C., Choi, Y., \& Kim, J. (2018). Testing a cultural orientation model of electronic word-of-mouth communication: A comparative study of U.S. and Korean Social media users. Asian Journal of Communication, 28(1), 74-92.

Lee, J. E., Cho, J. R., \& Stoel, L. (2012). Store attributes as determinants of store loyalty-moderating effect of rural versus urban apparel shoppers. The Research Journal of the Costume Culture, 20(1), 99-110.

Lee, M., \& Youn, S. (2009). Electronic word of mouth (e-wom). How e-wom platforms influence consumer product judgement. International Journal of Advertising, 28(3), 473-499.

Lee, M., \& Seounmi, Youn (2009). Electronic word of mouth (e-wom): How e-wom platforms influence consumer product judgement. International Journal of Advertising, 28.

Lee, J., Park, D. H., \& Han, I. (2008). The effect of negative online consumer reviews on product attitude: an information processing view. Electronic Commerce Research and Applications, 7(3), 341-352.

Lin, P. J., Jones, E., \& Westwood, S. (2009). Perceived risk and risk-relievers in online travel purchase intentions. Journal of Hospitality Marketing and Management, 18(8), 782-810.

Lin, T., \& Fang, C. (2006). The effects of perceived risk on the word-of-mouth communication DYAD. Social Behavior and Personality: An International Journal, 34, 1207-1216.

Loomes, G., \& Sugden, R. (1982). Regret theory: An alternative theory of rational choice under uncertainty. The Economic Journal, 92(368), 805-824.

Money, R. B., Gilly, M. C., \& Graham, J. L. (1998). Explorations of national culture and word-of-mouth referral behavior in the purchase of industrial services in the United States and Japan. Journal of Marketing, 62, $76-87$.

Murray, K. B. (1991). A test of services marketing theory: Consumer information acquisition activities. Journal of Marketing, 55(1), 10-25.

Parikh, A., Behnke, C., Vorvoreanu, M., Almanza, B., \& Nelson, D. (2014). Motives for reading and articulating usergenerated restaurant reviews on Yelp.com. Journal of Hospitality and Tourism Technology, 5(2), 160-176.

Park, C. \& Lee, T. M. (2009). Information direction, website reputation and e-wom effect: A moderating role of product type. Journal of Business Research, 62(1), 61-67

Park, D. H., \& Kim, S. (2008). The effects of consumer knowledge on message processing of electronic word-of-mouth via online consumer reviews. Electronic Commerce Research and Applications, 7(4), 399-410.

Purnawirawan, N., Pelsmacker, P., \& Dens, N. (2012). Balance and sequence in online reviews: How perceived usefulness affects attitudes and intentions. Journal of Interactive Marketing, 26(4), 244-55.

Rishika, R., Kumar, A., Janakiraman, R., \& Bezawada, R. (2013). The effect of customers' social media participation on customer visit frequency and profitability: An empirical investigation. Information Systems Research, 24(1), 108127.

Schumann, J. H., Wangenheim, F., Stringfellow, A., Yang, Z., Blazevic, V., Praxmarer, S., Shainesh, G., Komor, M., Shannon, R. M., \& Jiménez, F. R. (2010). Cross-cultural differences in the effect of received word-of-mouth referral in relational service exchange. Journal of International Marketing, 18(3), 62-80.

Senecal, S., \& Nantel, J. (2004). The influence of online product recommendations on consumers' online choices. Journal of Retailing, 80(2), 159-169.

Siegrist, M., Gutscher, H., \& Earle, T. C. (2005). Perception of risk: The influence of general trust, and general confidence. Journal of Risk Research, 8(2), 145-156.

Singelis, T., Triandis, H., Bhawuk, D., \& Gelfand, M. (1995). Horizontal and vertical dimensions of individualism and collectivism: A theoretical and measurement refinement. Cross-Cultural Research, 29(3), 240-275.

Skowronski, J. J., \& Carlston, D. E. (1989). Negativity and extremity in impression formation: A review of explanations. Psychology Bulletin, 105, 131-42.

Skowronski, J. J., \& Carlston, D. E. (1987). Social judgment and social memory: The role of cue diagnosticity in negativity, positivity, and extremity biases. Journal of Personality and Social Psychology, 52(4), 689-699. 
Sohn, D. (2009). Disentangling the effects of social network density on electronic word-of-mouth (e-wom) intention. Journal of Computer Mediated Communication, 14(2), 352-67.

Spence, K. W. (1960). Behavior theory and learning: Selected papers. New Haven, CT: Yale University Press.

Spence, K. W. (1956). Behavior theory and conditioning. New Haven, CT: Yale University Press.

Stauss, B. (1997). Global word of -mouth: Service bashing on the internet is a thorny issue. Marketing Management, 6(3), 28-30.

Stephen, A. T., \& Galak, J. (2012). The effects of traditional and social earned media on sales: A study of a micro lending marketplace. Journal of Marketing Research, 49(5), 624-639.

Stone, E. R., Yates, A. J., \& Caruthers, A. S. (2002). Risk taking in decision making for others versus the self. Journal of Applied Social Psychology, 32(9), 1797-1824

Straub, D., Loch, K., Evaristo, R., Karahanna, E., \& Srite, M. (2002). Toward a theory-based measurement of culture. Journal of Global Information Management (JGIM), 10(1), 13-23.

Sweeney, J., Soutar, G., \& Mazzarol, T. (2014). Factors enhancing word-of-mouth influence: Positive and negative service-related messages. European Journal of Marketing, 48(1/2), 336-359.

Sun, T., Youn, S., Wu, G., \& Kuntaraporn, M. (2006). Online word-of-mouth (or mouse): An exploration of its antecedents and consequences. Journal of Computer-Mediated Communication, 11(4).

Thibaut, J. W., \& Kelley, H. H. (1959). The social psychology of groups. New York: John Wiley \& Sons, Inc.

Xie, K., \& Lee, Y. J. (2015). Social media and brand purchase: quantifying the effects of exposures to earned and owned social media activities in a two-stage decision making model. Journal of Management Information Systems, 32(2), 204-238.

Ward, J. C., \& Ostrom, A. L. (2006). Complaining to the masses: The role of protest framing in customer-created complaint web sites. Journal of Consumer Research, 33(2), 220-230.

Wong, H., \& Chan, R. (1999). Relationship marketing in China: Guanxi, favoritism and adaptation. Journal of Business Ethics, 22(1), 107-118.

Yan, Q., Wu, S., Wang, L., Wu, P., Chen, H., \& Wei, G. (2016). E-wom from e-commerce websites and social media: Which will consumers adopt? Electronic Commerce Research and Applications, 17, 62-73.

Yap, K., Soetarto, B., \& Sweeney, J. (2013). The relationship between electronic word-of-mouth motivations and message characteristics: The sender's perspective. Australasian Marketing Journal, 21(1), 66-74.

Yaveroğlu, I. S., \& Donthu, N. (2002). Cultural influences on the diffusion of new products. Journal of International Consumer Marketing, 14(4), 49-63.

Yeniyurt, S., \& Townsend, J. D. (2003). Does culture explain acceptance of new products in a country? An empirical investigation. International Marketing Review, 20(4), 377-396.

Yoo, C. W, Sanders, L. G., \& Moon, J. (2013). Exploring the effect of e-wom participation on e-loyalty in e-commerce. Decision Support Systems, 55(3), 669-678. 
This Page Intentionally Left Blank 